\title{
PSYCHOGERIATRIC DIAGNOSES IN OLD PEOPLE'S HOMES AND NEGATIVE HEALTH BEHAVIOR
}

\author{
Spomenka Tomek-Roksandić ${ }^{1}$, Ivana Popek ${ }^{2}$, Nada Tomasović Mrčela ${ }^{1}, Z_{\text {Zvonimir Šostar }}{ }^{1}$, \\ Branko Kolarić ${ }^{1}$, Nina Smolej Narančić ${ }^{3}$, Ana Stavljenić Rukavina ${ }^{4} \&$ Mate Ljubičić ${ }^{5}$ \\ ${ }^{1}$ Reference Centre for Health Care of the Elderly of the Ministry of Health of the Republic of Croatia, \\ Center of Health Gerontology, Andrija Štampar Teaching Institute of Public Health, Zagreb, Croatia \\ ${ }^{2}$ Institute of Public Health of Sisak-Moslavina County, Sisak, Croatia \\ ${ }^{3}$ Institute of Anthropological Research, Zagreb, Croatia \\ ${ }^{4}$ DIU Libertas International University, Zagreb, Croatia \\ ${ }^{5}$ Croatian Medical Association, Croatian Society for Gerontology and Geriatrics, Zagreb, Croatia
}

received: 14.9.2016;

revised: 16.5.2017;

accepted: 14.6 .2017

\section{SUMMARY}

Background: The study was designed as a gerontologic-public health analysis of the relationship between the leading and accompanying psychogeriatric diagnoses and negative health behaviors recorded in the old people's home users, with the aim to evaluate and redefine gerontologic-public health priorities and geroprophylactic measures, with special reference to persons suffering from Alzheimer's disease and other dementias.

Subject and methods: Gerontologic-public health indicators obtained by monitoring health care needs of the elderly in specific institutional primary health care at 10 old people's homes $(N=1185)$ in Croatia in 2013 were analyzed using the professional methodology developed at Department of Health Gerontology, Andrija Štampar Teaching Institute of Public Health (Registry List 1 that refers to monitoring specific primary health care needs of elderly at old people's homes).

Results: Study results revealed that essential arterial hypertension was the principal (leading) principal diagnosis in the old people's home users as of 2013, accounting for 13\% of all leading diagnoses recorded in the elderly in institutional health care. In the study population, psychogeriatric diagnoses were recorded among the first five accompanying and leading diagnoses. Refusal of occupational therapy was the most common unfavorable health behavior recorded in the old people's home users, accounting for $22 \%$, followed by poor personal and environmental hygiene (19\%), physical inactivity (18\%), mental inactivity (15\%), obesity (13\%) and smoking (5\%) of 861 unfavorable behaviour characteristics recorded in study subjects. Study results showed the leading diagnoses in the old people's home users (such as circulatory system diseases, hip fracture, non-insulin dependent diabetes mellitus) to be associated with negative health behaviors that can be considered as risk factors for the development or progression of the disease, in psychogeriatric patients in particular.

Conclusions: The results obtained by gerontological-public health indicator analysis indicate that programs of geroprophylaxis, gerontologic and psychogeriatric measures should be implemented in old people's homes as a priority, with day centers for Alzheimer's disease patients. It is necessary to identify and evaluate risk factors for the occurrence of preventable diseases, change the negative health behaviors in the elderly, and apply the nutritional-gerontologic dietary standards at old people's homes including follow up of dietary intake of nutrients such as vitamins and mineral, with special reference to psychogeriatric patients.

Key words: elderly - psychogeriatric patients - geroprophylactic measures - health behavior - functional disability - leading diagnoses - old people's home

$$
* * * * *
$$

\section{INTRODUCTION}

Analysis of gerontology-public health indicators about health needs and functional ability of the elderly directs the development and implementation of gerontology-public health measures. Gerontological health measures, along with applying an individualized approach to gerontology and technical methodologies, also include monitoring, research, coordination, evaluation, reporting and planned projection of gerontology public health indicators of health needs and functional abilities of the elderly in institutional and non-institutional health care system.

Assessment of demographic indicators for 2011 showed that $17.09 \%$ of the Croatian population were aged $\geq 65$, while gender differentiation yielded $20.14 \%$ of elderly women and $13.81 \%$ of elderly men (TomekRoksandić et al. 2013).

According to the United Nations classification, Croatia belongs to the group of countries with very old population, which indicates the necessity of continuous development and improvement of gerontological-health measures and promotion of healthy active productive aging (Tomek-Roksandić et al. 2006).

The Croatian gerontological approach with implementation of an integral program of health care for the elderly is directed towards appropriate structure of all levels of health care management, i.e. high, intermediate and basic management, and their interaction (Tomek-Roksandić et al., 2006). The main task is active and co-responsible inclusion of the elderly and efficient interconnecting of all systems involved in 
health care for the elderly, from local community through the community at large (Duraković et al. 2007).

In 2008, the Center of Health Gerontology, Andrija Stampar Teaching Institute of Public Health formed gerontological database which showed that $2 \%$ of persons aged $\geq 65$ were accomodated at old people's homes (OPHs) in Croatia, which was below the European average of $4 \%$ (Tomek-Roksandić et al. 2013).

In this study performed in Croatia in 2013, the gerontology-public health indicators were analyzed, including principal diagnoses and unfavorable health behavior of the elderly in OPHs, as well as their connection. Based on the results, priority gerontologicalpublic health measures were designed, the implementation of which would support the establishment of health care management for the elderly.

\section{SUBJECTS AND METHODS}

Croatian gerontological methodology developed at the Center of Health Gerontology, Andrija Štampar Teaching Institute of Public Health in Zagreb was used. The methodology is based on defined characteristics for determination, recording, monitoring, studying and evaluation of health care needs of individual geriatric patients through the Registry of Healthcare Needs Monitoring in the Elderly (Official Gazette 82/02, $105 / 03,28 / 05,85 / 06,117 / 06$ and 126/06), requiring regular quarterly reporting and final reporting at the end of the current year. The information used in this paper was collected from the Registry List 1 that refers to monitoring specific primary health care needs of the elderly at OPHs and other social care institutions.

Data on 10 OPHs from all over Croatia were collected:

- Sveti Nikola Old People's Home (Krapina),

- Primum Nursing Home (Vukovar),

- Osijek Old People's Home (Osijek),

- Vela Luka Old People's Home (Korčula),

- Ščavničar (Selnica),

- Ćorluka Nursing Home (Zagreb),

- Udbina Old People's Home (Udbina),

- Ćorluka Sanatorium (Zagreb),

- Dom Sestra Maca Home (Zagreb) and

- Trnje Old People's Home (Zagreb).

The sample in this study comprised a total of 1185 participants.

The characteristics of unfavorable health behavior defined according to the following categories were identified: poor personal and environmental hygiene; physical inactivity; mental inactivity; refusing occupational therapy; obesity; smoking; lack of moderate sun exposure; taking medication without any control; alcoholism; drinking black coffee more than two small cups a day; and non-compliance with the instructions of doctors. Finally, the principal diagnoses (multiple diagnoses are quite likely to exist in elderly individuals) as defined by the ICD $10^{\text {th }}$ revision classification were determined (Kuzman 1994). Both the health behavior characteristics and the diagnoses were noted by the teams of general practitioners/family medicine. Data are presented as proportions numerically and graphically, as well as relationship between the most common unfavorable health behaviors and principal diagnoses recorded in the users at $10 \mathrm{OPHs}$ in Croatia.

\section{RESULTS}

Essential arterial hypertension was the most common principal diagnosis in the OPH users in Croatia in 2013 , accounting for $13 \%$ of all principal diagnoses recorded in these subjects $(\mathrm{N}=1185)$.

After arterial hypertension, the next five most common principal diagnoses were cardiomyopathy (I $42 ; 12 \%$ ), cerebrovascular disease sequels (I 69; 9\%), personality and behavior disorders caused by disease, brain damage and dysfunction (F07; 8\%), and diabetes mellitus type 2 (E $11 ; 6 \%$ ).

According to the Registry List 1, refusing occupational therapy was the most common component of unfavorable health behavior recorded in the OPH users, which accounted for $22 \%$ of 861 unfavorable behavior characteristics recorded in study subjects $(\mathrm{N}=1185)$. The next five most common adverse health behaviors were poor personal and environmental hygiene (19\%), physical inactivity (18\%), mental inactivity (14\%), obesity (13\%) and smoking (5\%). According to the research, 0.73 negative health behaviors per person were recorded.

The relationship between the leading diagnosis and negative health behavior (Figure 1,2) in OPH users in Croatia in 2013 indicated the following associations to be most common:

- for the diagnosis of hip fracture $(n=50)$ : alcoholism $(16.0 \%)$ and drinking black coffee more than two small cups a day (12.50\%);

- for cerebrovascular disease sequels $(n=100)$ : predominantly failure to maintain personal hygiene and environmental hygiene $(10.32 \%)$ and then refusing occupational therapy $(9.31 \%)$;

- for cardiomyopathy $(\mathrm{n}=146)$ : lacking moderate sun exposure $(30 \%)$ and uncontrolled use of medications $(28.57 \%)$;

- for essential arterial hypertension $(n=154)$ : alcoholism (20\%) and obesity (19.69\%):

- for Parkinson's disease in beneficiaries $(n=38)$ : lacking moderate sun exposure (6.67\%) and mental inactivity $(4.61 \%)$,

- for the diagnosis of schizophrenia $(n=35)$ : drinking more than two small cups of black coffee a day (12.5\%) and smoking (7.89\%),

- for personality and behavior disorders caused by disease, brain damage and dysfunction $(n=91)$ : poor personal and environmental hygiene (7.83\%) and refusing occupational therapy $(6.61 \%)$, 
- for the diagnosis of non-specific dementia $(n=41)$ : psychological (4.15\%) and physical inactivity $(4.15 \%)$,

- for vascular dementia $(n=37)$ : poor personal and environmental hygiene (4.27\%) and mental inactivity $(4.15 \%)$,
- for cerebral infarction $(n=61)$ : physical inactivity $(8.3 \%)$ and noncompliance with the instructions of doctors $(7.58 \%)$,

- for diabetes mellitus type $2(n=75)$ : uncontrolled medication (28.57\%) and obesity (12.95\%), and

- for breast cancer $(n=36)$ : smoking $(5.26 \%)$ and mental inactivity $(3.20 \%)$.

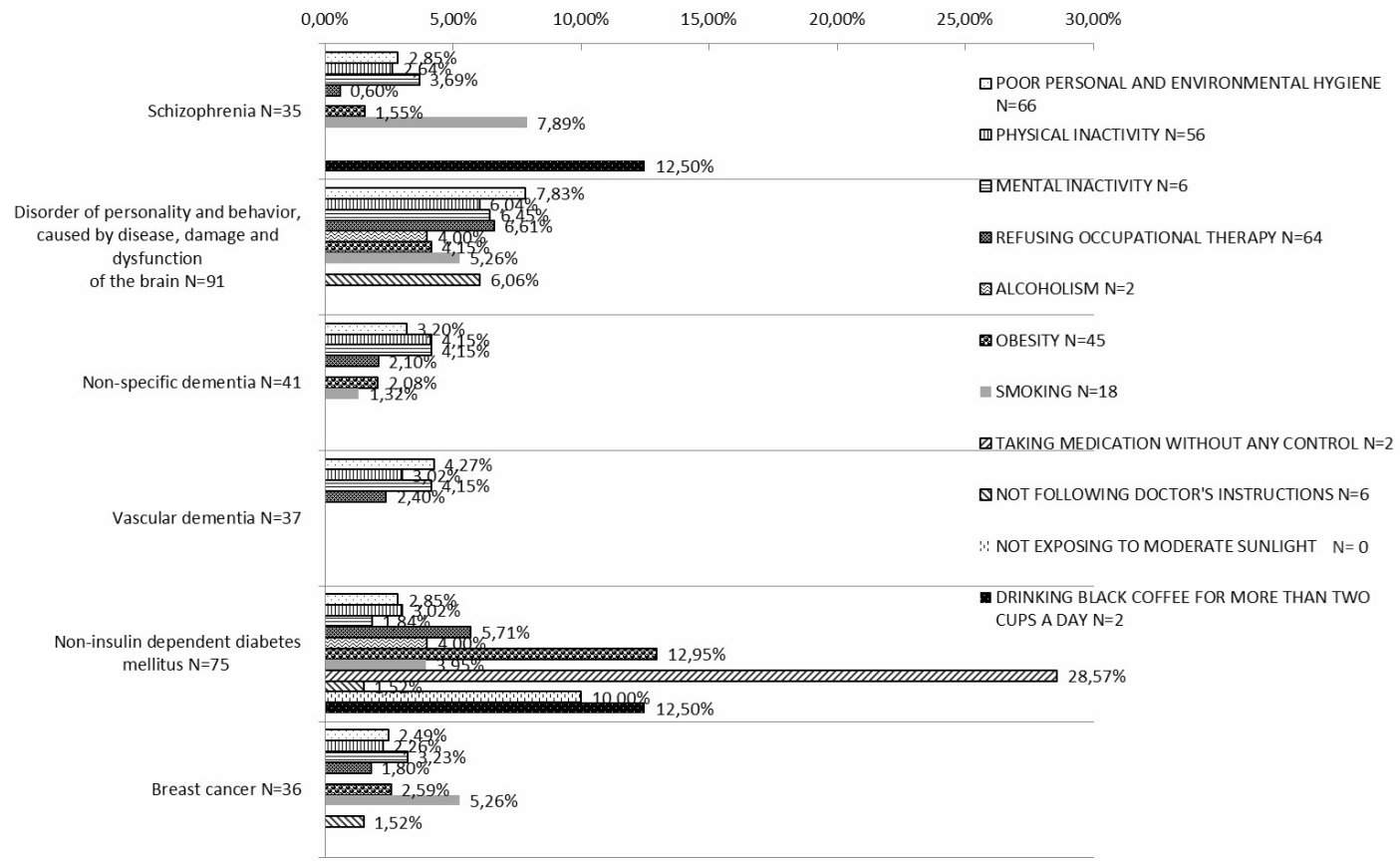

Figure 1. The relationship between the principal diagnoses and the most common unfavourable health behaviours recorded in the Old People's Home users in Croatia, 2013

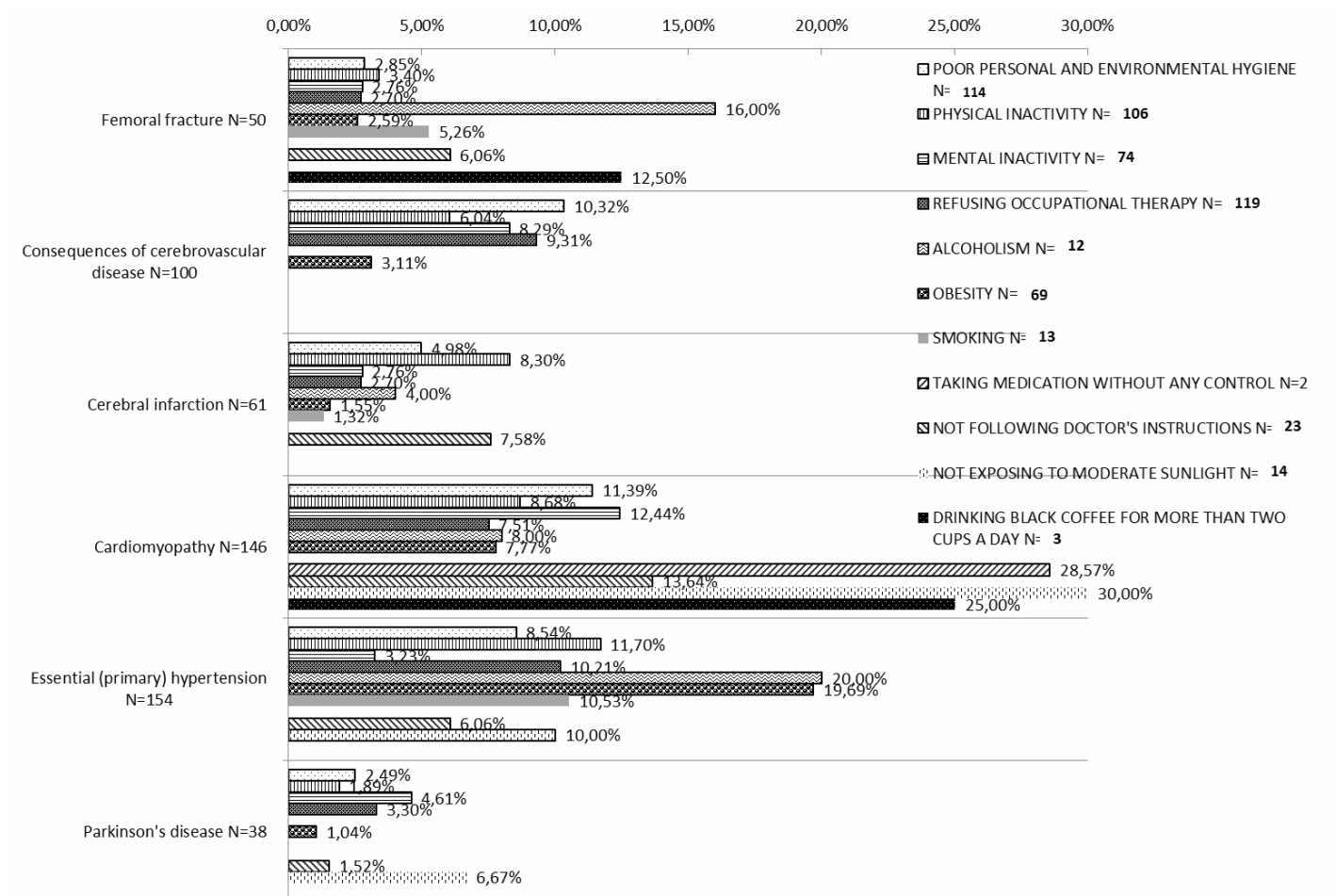

Figure 2. The relationship between the principal diagnoses and the most common unfavourable health behaviours recorded in the Old People's Home users in Croatia, 2013 


\section{DISCUSSION}

Essential arterial hypertension was found to be the most common principal diagnosis in the OPH users, pointing to the need of targeted measures of prevention. This finding recorded in elderly population is consistent with the high prevalence of arterial hypertension in the adult population of Croatia, i.e. in the 18-64 age groups (Turek et al. 2001).

The diagnoses which are often the cause of accommodation in the OPH (such as essential aretrial hypertension, cerebrovascular disease sequels, cerebral infarction, hip fracture, nonspecific dementia, vascular dementia and diabetes mellitus type 2) were associated with negative health behaviors that can be considered as risk factors for the development or progression of the disease (Figure 1,2). This indicates the need for re-evaluation and improvement of the programs of primary, secondary and tertiary prevention in $\mathrm{OPH}$.

Public health data on health care needs of the elderly ensure an integral primary health care and implementation of the Program of Health Care Measures and Procedures in Health Care of the Elderly, which includes primary, secondary and tertiary prevention (Tomek-Roksandić et al. 2013).

Primary prevention is directed towards prevention of pathological aging, with the key role in the control of chronic non-communicable diseases (such as cardiovascular and cerebrovascular diseases) by influencing the modifiable risk factors, in particular inadequate physical activity, unhealthy dietary habits, cigarette smoking, etc. (Duraković 2007, Jakšić et al. 2013, Jakovljević 2004). The measures of secondary prevention for the elderly encompass testing for preventable diseases and target check-ups, in order to timely detect the diseases that can be controlled or eliminated by appropriate treatment (Tomek-Roksandić et al. 2013, Ebling \& Eljuga 1998). Tertiary prevention measures for the elderly include the use of various health procedures with the aim to prevent further physical and mental decompensation of the elderly already suffering from some diseases and to preserve their functional ability.

Implementation of the measures of primary, secondary and tertiary prevention enables prevention of disease and functional disablement in the elderly, which is the prime gerontology-public health role.

The known primary prevention measures that have an impact on reducing the incidence of hypertension and imply lifestyle modification include reduced salt intake, body mass reduction in overweight people, no smoking, increased physical activity, moderate alcohol consumption, use of diet with more fruits and vegetables, less fat, and others (Reiner \& Tedeschi-Reiner 2005, KrouselWood et al. 2004).

Arterial hypertension is recognized as a preventable risk factor for the occurrence of cardiovascular diseases (Krousel-Wood et al. 2004). Cardiovascular diseases belong to the group of circulatory diseases, which are the leading cause of death in the elderly in Croatia (Reiner \& Tedeschi-Reiner 2005).

Gerontological-public health measures aiming at preventing the prevailing hypertension in geriatric population include following gerontological recommendations on the salt intake limit (no more than $5 \mathrm{~g} /$ day), implementation of the Program of Primary, Secondary and Tertiary Prevention for the Elderly and Development of Positive Health Behaviors.

The rules on healthy diet for the elderly consisting of eight dietary rules have been designed in line with the Croatian Dietary Guidelines for the Elderly (Vranešić-Bender et al. 2011), taking due consideration of their health state, energy requirements and physical activity. These rules include an adequate dietary energy intake, regularly distributed during the day, balanced daily meals with the intake of protein, fat, carbohydrates and fibers at the recommended ratios, varied food intake including fruit and vegetables, adequate fluid intake and reduced dietary intake of 5 W's ('whites'): salt, sugar, white flour, fat and white rice (Vranešić-Bender et al. 2011).

The purpose of dietary rules for the elderly is the prevention of ill-aging, health improvement and preservation of seniors' functional abilities. Also, these rules are one of the main geroprophylactic measures of primary prevention for the elderly.

\section{Geroanthropometry in the assessment of nutritional status}

Assessment of the nutritional status in geriatric population is especially focused on the registration of obesity, which causes considerable health issues, and to timely detect the risk of malnutrition as a result of specific physical, social, psychological and economic changes that characterize the aging process (Duraković et al. 2007).

Malnutrition in hospitalized elderly patients may pose an increased risk for their morbidity and mortality, higher incidence of decubital wounds, poor wound healing, increased susceptibility to infections, prolonged stay in stationary institutions, and increased costs for the health system (Duraković et al. 2007).

Epidemiological studies estimate that exposure to malnutrition in hospitalized elderly is up to $65 \%$, while in the OPHs it is 19\%-36\% (Vranešić-Bender et al. 2011).

Anthropometric measurements that are most commonly used in the assessment of nutritional status of the elderly are body weight and body mass index (BMI), skinfolds and circumferences of the extremities and trunk (Vranešić-Bender et al. 2011). Geroanthropometry has now recognized that the cut-off values used for the middle aged people are not valid for the elderly, especially for people of very old age, as also indicated 
by recent Croatian studies (Tomek-Roksandić 2009, Rudan 2002) conducted among people aged 85-101 (Tomek-Roksandić 2009).

The guidelines have adopted BMI $22 \mathrm{~kg} / \mathrm{m}^{2}$ as a limit value that indicates the risk of malnutrition in the elderly.

Besides BMI, in order to estimate nutritional status of the elderly, additional anthropometric measurements are recommended (height of the knee, upper arm and lower leg circumference, and skinfolds on upper arm and back), especially when it is impossible to take direct measurements of the body height and weight of the elderly (Vranešić-Bender et al. 2011).

According to the guidelines of geroanthropometry, lower leg circumference is an important measure of the amount of the loss of muscle tissue due to reduced physical activity. Similarly, a reduced upper arm and lower leg circumference shows better correlation with malnutrition than BMI, and the association is more significant in the sick elderly (Chumlea et al. 1995).

According to the guidelines, in case of malnutrition or merely of the risk of developing malnutrition, oral dietary supplements (enteral formulas) are recommended for both hospitalized geriatric population and those in nursing homes for the elderly, as well for those living in the community (Vranešić-Bender et al. 2011). It is recommended to be applied in case of confirmed insufficient food intake, unintentional 5\% weight loss over 3 months or $10 \%$ over 6 months, and $\mathrm{BMI}<22 \mathrm{~kg} / \mathrm{m}^{2}$ (Volkert et al. 2006).

It is known that energy intake is lower in elderly population, so that daily energy requirements are lower by $10 \%$ between the ages of 51-75 years, and then reduced by another $10 \%$ per decade (Vranešić-Bender et al. 2011). The amount of water is usually calculated so that about $30 \mathrm{~mL} / \mathrm{kg}$ of water is provided per day, $\mathrm{i}$. e., $100 \mathrm{~mL} / \mathrm{kg}$ for the first $10 \mathrm{~kg}, 50 \mathrm{~mL} / \mathrm{kg}$ for the next $10 \mathrm{~kg}$ and $15 \mathrm{~mL} / \mathrm{kg}$ for the remaining weight, together with individual gerontological approach (Vranešić-Bender et al. 2011).

The guidelines suggest that physician in primary health care or a nutritional team (doctor, nurse, nutritionist and pharmacist) in hospitals and OPHs routinely assess nutritional status of persons over 65 once a year, and of people over 75 even more often, if necessary (Vranešić-Bender et al. 2011).

The application of validated methods is recommended, i.e. Nutrition Risk Screening 2002 (NRS 2002) to assess nutritional status of hospitalized elderly patients; Mini Nutritional Assessment (MNA) for people in OPHs and for the general population; and Malnutrition Universal Screening Tool (MUST) for all elderly (Vranešić-Bender et al. 2011).

Croatian guidelines for nutrition of the elderly are primarily directed towards assessment of the nutritional status of the elderly who are at risk of malnu- trition, defining specific nutritive needs of the elderly and selecting the most appropriate nutritive supports.

\section{Functional disability of the elderly relative to their mental state}

According to the methodology developed at the Reference Center of Gerontology of the Ministry of Health of the Republic of Croatia, Andrija Stampar Teaching Institute of Public Health, functional ability in $\mathrm{OPH}$ users is assessed in two categories, i.e. mobility (physical state) and independence (mental state).

Although it is a conventional wisdom that the course of aging is generally accompanied by the loss of physical ability, elderly people are at a greater risk of losing their cognitive functions (Kueider et al. 2014). Analysis of gerontologic data from the Registry List 1 (monitoring health care needs), collected at the selected OPHs in 2014, showed impairments of mental functioning to be present in the majority of subjects, resulting in restricted independence $(38.88 \%)$, permanent independence (46.34\%) and unable to respond (12.12\%). At the same time, various levels of impaired mobility were recorded, as follows: restricted mobility $(32.71 \%)$, permanently restricted mobility $(26.54 \%)$ and permanent immobility (10.71\%). In the selected OPHs, diagnoses from the group of mental and behavioral disorders (F00F99) were the second leading diagnoses (14.49\%) and the first accompanying diagnoses $(13.10 \%)$. The most common leading and accompanying diagnoses from this group of disorders recorded in $\mathrm{OPH}$ users were personality and behavioral disorders caused by disease and brain damage and dysfunction (F07); other mental disorders caused by brain damage and dysfunction and physical illness (F06); schizophrenia (F20); and depression (F32). According to data on the most common reasons for hospitalization in 2014, mental and behavioral disorders (F00-F99) ranked tenth in the $>65$ age group and second in the $<65$ age group In comparison to 2016, this group of disorders also ranked tenth and second as the reason for hospitalization in the populations aged $>65$ and $<65$, respectively clearly indicating that mental disorders pose a major public health problem already in younger age groups.

Due to the ever growing prevalence of psychogeriatric diseases in the elderly accommodated in OPHs, psycholeptics rank as the leading prescription drugs (Mimica \& Presečki 2012.). Results of recent studies show that decline in cognitive functioning need not inevitably occur in the elderly; the more so, recognizing risk factors for cognitive function impairment and preventive activities are more efficient than subsequent medication (Kueider et al. 2014). In addition, differential diagnostic approach should be used to establish the possible vitamin deficiencies, vitamin B12 in particular, in psychogeriatric patients (Lachner et al. 2014). 
As decline of cognitive functions leads to the loss of independence, it is of utmost importance to preseve cognitive functioning as a precondition of independent functioning and ability of independent living and decision making. The main recommendations for preserving and upgrading mental health and cognitive abilities in the elderly include stimulation of mental and physical activity, healthy dietary habits, and maintaining social interactions (Brodziak et al. 2015).

\section{Program of gerontological health measures}

Gerontological-public health measures prevent morbidity and functional disability of the elderly and cover the change of negative health behavior in the elderly, timely identification of the risk factors for the development of unhealthy aging, and encourage selfresponsibility for their own health during aging .

The present study pointed to physical inactivity as the most common characteristic of unfavorable health behavior, which would certainly require priority measures in health promotion for the elderly. For this purpose, it is proposed to improve monitoring and evaluation program of regular physical and mental activities for elderly home care users, according to their functional abilities and individual gerontological approach (Tomek-Roksandić et al. 2013). Measures of prevention for the elderly are to be provided by an interdisciplinary team of gerontologists, a team of family medicine physicians, geriatric nurses, physiotherapists, nutritionists and gerontokinesiologists/ gerontoanthropologists and other experts of various specialties including gerontology public health manager (Scarmeas et al. 2009, Nemoto et al. 2007, Rydwik et al. 2005, Johannsen et al. 2008).

\section{The Croatian Model of Gerontologic Healthcare Management for the Elderly}

Center of Health Gerontology, Andrija Štampar Teaching Institute of Public Health, as Reference Center for Health Care of the Elderly of the Ministry of Health of the Republic of Croatia, provides a high level of healthcare management for the elderly through monitoring of health care needs and functional disablement of this population segment.

County Centers of Gerontology (currently being established) perform the activities of medium healthcare management for the elderly. Keeping gerontological databases at the county level will provide a basis for development of the Program of Healthcare Measures and Procedures in Healthcare of the Elderly (Duraković et al. 2007).

Basic healthcare management for the users of institutional and non-institutional care for the elderly is provided through Centers of Gerontology, OPHs, primary health care, geriatric hospitals, rehabilitation facilities, day-hospitals for geriatric patients, and geronto- host service for the elderly in their local community (Tomek-Roksandić et al. 2006).

The team of general practitioners/family physicians with geriatric nurses has the key role in healthcare of the elderly, especially in specific primary health care (in elderly care homes), also including other profiles of experts (psychogeriatrics, cardiology, neurogeriatrics, etc.) through an interdisciplinary gerontology approach. Such an integrated gerontological program includes primary, secondary and tertiary prevention for the elderly, targeted health promotion, preservation of functional capacity and extending of active life. This rationalizes geriatric health spending, reduces morbidity, disability and mortality in the early (65-74 years) and middle (75-84 years) old age. Gerontological health measures have been primarily aimed at preserving functional abilities of the elderly, improving health and ensuring healthy and active aging (Duraković et al. 2011, 2013).

\section{Limitations of the study}

In OPHs, there is a considerable problem of turnover of health professionals, general/family medicine teams in particular, which entails constant changes in the mode of continuous monitoring and evaluation of healthcare needs, morbidity, negative health behaviors and functional disability of geriatric beneficiaries. This high turnover is caused by the demanding healthcare needs of functionally disabled geriatric patients. In addition, the institutionalized care suffers from the lack of particular professionals, suchs as psychiatrists and psychologists to deal with prevention, diagnosis, management and follow up of psychogeriatric disorders. Therefore, it is mandatory to develop a plan of compulsory continuous education and re-education of professionals in geriatrics, gerontology and psychogeriatrics to work with the elderly population.

\section{CONCLUSION}

The results obtained by the gerontological-public health analysis in Croatia in 2013 indicate the application of innovative integrated programs of gerontological-public health measures of primary, secondary and tertiary prevention in OPHs. These programs should be focused on timely identification of the risk factors for the occurrence of preventable diseases, especially circulatory diseases, and on changing the prevailing negative health behaviors in older persons, e.g., refusing occupational therapy, poor personal and environmental hygiene, and physical and mental inactivity. It is imperative to apply the Croatian guidelines for nutrition of the elderly and the nutritional gerontological norms in the OPHs for the purpose of geroprophylaxis and treatment of geriatric patients. In addition, systematic follow up of the recorded psychogeriatric patients through the national Registry is required. 


\section{Acknowledgements: None.}

\section{Conflict of interest: None to declare.}

\section{Contribution of individual authors:}

Spomenka Tomek Roksandić: concieved of the study, design of the study, participating and coordinating the study, literature research;

Ivana Popek: drafting and manuscript writing, statistical analisys, literature research;

Nada Tomasović Mrčela: collecting data, literature research, writing the paper, statistical analisys;

Branko Kolarić: interpretation of the data and literature research;

Nina Smolej Narančić: interpretation of the data, writing the paper, literature research;

Ana Stavljenić Rukavina: literature research, participating in analisys and interpretating of data;

Zvonimir Šostar: participating in study and literature research;

Mate Ljubičić: participating in study and literature research.

\section{References}

1. Brodziak A, Wolinska A, Kolat E, Rozyk-Myrta A: Guidelines for prevention and treatment of cognitive impairment in the elderly. Med Sci Monit 2015; 21:585-97.

2. Chumlea WC, Guo SS, Vellas BJ, Guigoz Y: Techniques of assessing muscle mass and function (sarcopenia) for epidemiological studies of the elderly. J Gerontol 1995; 50A:45-54.

3. Duraković Z, et al.: Gerijatrija (Geriatrics). C.T. Poslovne informacije d.o.o., Zagreb, 2007. (in Croatian)

4. Duraković Z, et al.: Geriatric pharmacotherapy. C.T. Poslovne informacije d.o.o., Zagreb, 2011.

5. Duraković Z: Aging - gerontology public health management in Croatia. Period Biol 2013; 115:491-98.

6. Ebling Z, Eljuga D. Bolesti uzrokovane pušenjem. Ministarstvo zdravstva Republike Hrvatske. Zagreb, 1998.

7. Jakšić N, Aukst-Margetić B, Jakovljević M: Does personality play a relevant role in the placebo effect? Psychiatria Danubina 2013; 25:17-23.

8. Jakovljević M: Depresivni poremećaji: od ranog prepoznavanja do uspješog liječenja (Depressive disorders: from early recognition to successful treatment). Pro Mente, Zagreb, 2004. (in Croatian)

9. Johannsen DL, et al.: Physical activity in aging: comparison among young, aged and nonagenarian individuals. J Appl Physiol 2008; 105:495-501.
10. Krousel-Wood MA, Muntner P, He J, Whelton PK: Primary prevention of essential hypertension. Med Clin North Am 2004; 88:223-38.

11. Kueider A, Bichay K, Rebok G: Cognitive training for older adults: what is it and does it work? American Institutes for Reseach, October 2014.

12. Kuzman M (ed): Međunarodna klasifikacija bolesti $i$ srodnih zdravstvenih problema (International Classification of Diseases and Related Health Problems). Medicinska naklada, Zagreb, 1994. (in Croatian)

13. Lachner C, Martin C, John D, Nekkalapu S, Sasan A, Steinle $N$, et al.: Older adult psychiatric inpatients with non-cognitive disorders should be screened for vitamin B12 deficiency. The Journal of Nutrition, Health \& Aging 2014; 18:209-212.

14. Mimica N, Presečki P. Alzheimer's disease epidemiology, diagnosis and standard pharmacological treatment. Medix 2012; 18:100/101.

15. Nemoto K-I, Gen-no H, Masuki S, Okazaki K, Nose H, et al.: Effects of high-intensity interval walking training on physical fitness and blood pressure in middle-aged and older people. Mayo Clin Proc. 2007 ;82:803-11.

16. Reiner Ž, Tedeschi-Reiner E: Prevention of cardiovascular diseases in the elderly. Medicus 2005; 2:195-203. (in Croatian)

17. Rudan, P: Antropologija i medicina: studij populacijske strukture i neke mogućnosti novih spoznaja. 5th International Congress of Croatian Hospitals, Zagreb, 2002.

18. Rydwik E, Kerstin F, Akner G, et al.: Physical training in institutionalized elderly people with multiple diagnoses $-a$ control pilot study. Arch Gerontol Geriatrics 2005; 40:29-44.

19. Scarmeas N, Luchsinger JA, Schuph N, Brickman AM, Cosentino S, Tang MX, et al. Physical activity, diet, and risk of Alzheimer disease. JAMA 2009;302:627-37.

20. Tomek-Roksandić $S$, et al.: Zdravstveni management za starije (Health management for the elderly). Lijec Vjesn 2006; 128 (Suppl 1):27-8. (in Croatian)

21. Tomek-Roksandic S: Anthropometric Characteristics of the Centenarians. Doctoral dissertation. Zagreb, Prirodoslovno-matematički fakultet (Faculty of Science), 2009. (in Croatian)

22. Tomek-Roksandić S et al.: Program of primary, secondary and tertiary prevention for the elderly. Period Biol 2013a; 115:475-81.

23. Turek $S$, et al.: A large cross-sectioal study of health attitudes, knowledge, behaviour and risks in the post-war Croatian population (The First Croatian Health Project). Coll Antropol 2001; 25:77-96.

24. Volkert D, Berner YN, Berry E, et al.: ESPEN guidelines on enteral nutrition: geriatrics. Clin Nutr 2006; 25:330-59.

25. Vranešić-Bender D, et al.: Hrvatske smjernice za prehranu osoba starije dobi, I. dio (Croatian guidelines for nutrition in the elderly - Part I). Lijec Vjesn 2011; 133:1-10. (in Croatian)

Correspondence:

Spomenka Tomek-Roksandić, MD

Center of Gerontology, Andrija Štampar Teaching Institute of Public Health

Mirogojska 16, 10000 Zagreb, Hroatska

E-mail: spomenka.tomek-roksandic@stampar.hr 